International Journal of

Environmental Research and

Public Health

ISSN 1660-4601

www.mdpi.com/journal/ijerph

Article

\title{
Overweight and Obesity and Associated Factors among School-Aged Adolescents in Six Pacific Island Countries in Oceania
}

\section{Supa Pengpid ${ }^{1,2}$ and Karl Peltzer ${ }^{1,2,3, *}$}

1 ASEAN Institute for Health Development, Mahidol University, Salaya, Phutthamothon, Nkohn Pathom 73170, Thailand; E-Mail: supaprom@yahoo.com

2 Department of Research \& Innovation, University of Limpopo, Turfloop Campus, Sovenga 0727, South Africa

3 HIV/AIDS/STIs and TB (HAST), Human Sciences Research Council, Pretoria 0001, South Africa

* Author to whom correspondence should be addressed; E-Mail: karl.pel@mahidol.ac.th;

Tel.: +66-2-441-0207; Fax: +66-2-441-9044.

Academic Editor: Peter Clifton

Received: 18 August 2015 / Accepted: 7 September 2015 / Published: 13 November 2015

\begin{abstract}
The aim of this study was to assess overweight and obesity and associated factors in school-going adolescents in six Pacific Island countries in Oceania. The sample included 10,424 school-going adolescents predominantly 13-16 years old from Fiji, Kiribati, Samoa, Solomon Islands, Tonga, and Vanuatu. Bivariate and multivariable analyses were conducted to assess the relationship between dietary behaviour, substance use, physical activity, psychosocial factors, social-familial influences, and overweight or obesity. The prevalence of overweight and obesity was determined based on self-reported height and weight and the international child body mass index standards. Results indicate a prevalence of overweight or obesity of $24.3 \%$ and obesity of $6.1 \%$ in the six countries, ranging in terms of overweight or obesity and obesity from $12.0 \%$ and $0.4 \%$ in Vanuatu to $58.7 \%$ and $21.1 \%$ in Tonga, respectively. In multivariable regression analysis, being female was associated with overweight, carbonated soft drink use with obesity, sedentary behaviour with overweight or obesity, suicidal ideation with overweight, having close friends and peer support with overweight and obesity, parental or guardian supervision with overweight, and parental or guardian bonding was associated with overweight or
\end{abstract}


obesity. High prevalence rates of overweight and obesity were found and several factors identified which can help guide interventions.

Keywords: overweight; obesity; overweight or obesity; dietary behaviour; physical activity; sedentary behaviour; psychosocial factors; soico-familial factors; global school-based health survey; Oceania

\section{Introduction}

The prevalence of adolescent overweight and obesity seems to have been substantially increasing worldwide [1], including in low-income and middle-income countries [1], with a prevalence of $10 \%-20 \%$ in south-east Asian and western Pacific regions [2]. While there are studies reporting high rates of adult obesity in the Pacific Island countries in Oceania [3-6], fewer studies are found on childhood obesity. In secondary school children (age 12-18 years) in Fiji 16.7\% were overweight and $5.2 \%$ obese [7]. The prevalence of obesity in Tonga children (12-19 years) was $6.0 \%$ to $22.8 \%$ among girls and $2.2 \%-3.8 \%$ among boys depending on Island of residence and obesity classification [8], and in Vanuata $3 \%-6 \%$ in three islands overweight or obesity among boys and $0-11.4 \%$ among girls [9]. Ng et al. [10] estimated as part of the Global Burden of Disease Study 2013, a prevalence of overweight and obesity in Fiji 12.8\% among boys ( $<20$ years) and 24.9\% among girls; $47.7 \%$ and $66.1 \%$ among boys and girls, respectively, in Kiribati; $42.2 \%$ and $50.0 \%$ among boys and girls, respectively, in Samoa; $28.3 \%$ and $49.2 \%$ among boys and girls, respectively, in Solomon Islands; $34.5 \%$ and $52.6 \%$ among boys and girls, respectively, in Tonga; and $14.5 \%$ and $23.2 \%$ among boys and girls ( $<20$ years), respectively, in Vanuatu.

Childhood overweight and obesity have detrimental health consequences during childhood and adulthood [11]. In order to plan services for the provision of care and to evaluate the impact of policy strategies it is important to monitor the prevalence of obesity [12].

Factors identified in previous studies to be associated with overweight and/or obesity in adolescents include: (1) sociodemographic factors: male gender [13,14], female gender [15,16], younger age [13]; (2) dietary factors: sugar-sweetened beverages [17], frequently consumed fast food [18], lack of fruit consumption [19], not feeling hungry [16]; (3) Physical inactivity and high sedentary behavior [20]; (4) Other health risk behavior such as bullying victimization [21], smoking [22,23]; (5), psychosocial factors [24,25], including familial influences such as authoritative parenting style [26]. Some of these risk factors for adolescent obesity identified may differ in the Oceania study region. Therefore, the aim of this study was to assess overweight and obesity and associated factors in school-going adolescents in six Pacific Island countries in Oceania.

\section{Methods}

\subsection{Description of Survey and Study Population}

This study involved secondary analysis of existing data from the Global School-Based Health Survey (GSHS) from six Pacific Island countries in Oceania (Fiji 2010, Kiribati 2011, Samoa 2011, 
Solomon Islands 2011, Tonga 2010, and Vanuatu 2011). All Pacific Island countries from which GSHS datasets with the two-stage cluster sample design and Body Mass Index (BMI) information were publicly available were included in this secondary analysis. Details and data of the GSHS can be accessed [27] A two-stage cluster sample design was used to collect data to represent all students in grades $6,7,8,9$, and 10 in the country. At the first stage of sampling, schools were selected with probability proportional to their reported enrollment size. In the second stage, classes in the selected schools were randomly selected and all students in selected classes were eligible to participate irrespective of their actual ages. Students self-completed the questionnaires to record their responses to each question on a computer scanable answer sheet. The GSHS 10 core questionnaire modules address the leading causes of morbidity and mortality among children and adults worldwide: tobacco, alcohol and other drug use; dietary behaviors; hygiene; mental health; physical activity; sexual behaviors that contribute to HIV infection, other sexually transmitted infections, and unintended pregnancy; unintentional injuries and violence; protective factors and respondent demographics [27].

\subsection{Measures}

\subsubsection{BMI Measurement and Overweight Classification}

Body weight and height were assessed by self-report. School children with BMI figures relating to an adult BMI of $<25.0 \mathrm{~kg} / \mathrm{m}^{2}$ were categorized as having normal weight and those with a BMI of $\geq 25.0 \mathrm{~kg} / \mathrm{m}^{2}$ were categorized as having overweight, while those with a BMI value of $\geq 30.0 \mathrm{~kg} / \mathrm{m}^{2}$ ) were classified as obese. For the BMI cut-points used to define the different weight classifications, international age- and gender-specific criteria were used [28].

\subsubsection{Dietary Behaviour and Substance Use}

Carbonated soft drinks: "During the past 30 days, how many times per day did you usually drink carbonated soft drinks such as Pepsi, Seven-up, Fanta, Coke, etc." Response options ranged from $0=$ I did not drink any carbonated soft drinks in the past 30 days to $6=5$ or more times per day [27].

Eating food from a fast food restaurant: "During the past seven days, on how many days did you eat food from a fast food restaurant, such as such country specific examples?” Response options ranged from 0 to 7 days [27].

Fruits: "During the past 30 days, how many times per day did you usually eat fruit, such as 'country specific examples'?" Response options ranged from 1 = I did not eat fruit during the past 30 days to $7=5$ or more times per day [27].

Vegetables: "During the past 30 days, how many times per day did you usually eat vegetables, such as 'country specific examples'?" Response options ranged from 1 = I did not eat vegetables during the past 30 days to $7=5$ or more times per day [27].

Hunger: "During the past 30 days, how often did you go hungry because there was not enough food in your home?" Response options ranged from $1=$ never to 5 = always [27].

Substance Use. Smoking cigarettes: "During the past 30 days, on how many days did you smoke cigarettes?" Response options ranged from $1=0$ day to $7=$ all 30 days [27]. 
Alcohol use: "During the past 30 days, on how many days did you have at least one drink containing alcohol?" Response options ranged from $1=0$ day to $7=$ all 30 days [27].

\subsubsection{Physical Activity and Sedentary Behavior}

Leisure time physical activity was assessed with two questions: "During the past 7 days, on how many days were you physically active for a total of at least 60 min. per day?" and "During a typical or usual week, on how many days are you physically active for a total of at least 60 min per day?" Physical inactivity was classified as four or less days at least $60 \mathrm{~min}$. per day physically active in a week [27]. Students were also asked about how many days they had walked or rode a bicycle to or from school during the past seven days, and how many times they had attended a physical education class during each week during the school year [27].

Leisure time sedentary behavior: "How much time do you spend during a typical or usual day sitting and watching television, playing computer games, talking with friends, or doing other sitting activities?" [27].

\subsubsection{Psychosocial Factors and Socio-Familial Influences}

(1) Loneliness: "During the past 12 months, how often have you felt lonely?" (Response options ranged from 1 = never to 5 = always). (2) Anxiety or worried: "During the past 12 months, how often have you been so worried about something that you could not sleep at night?" (Response options ranged from 1 = never to 5 = always). (3) Suicidal ideation. "During the past 12 months, did you make a plan about how you would attempt suicide?" (Response option was yes or no). (4) No close friends: "How many close friends do you have?" (Response options ranged from $1=0$ to $4=3$ or more). (5) Bullied: Having been bullied at least once in the preceding 30 days, was classified as bullied [27]. Socio-familial influences were assessed with questions on peer support at school, parental or guardian supervision, connectedness, and bonding. Peer support at school was assessed with the question: "During the past 30 days, how often were most of the students in your school kind and helpful?" Parental or guardian supervision: "During the past 30 days, how often did your parents or guardians check to see if your homework was done?" Parental or guardian connectedness: "During the past 30 days, how often did your parents or guardians understand your problems or worries?" and Parental or guardian bonding: "During the past 30 days, how often did your parents or guardians really know what you were doing with your free time?" (Response options to these questions were from $1=$ never to $5=$ always) [27].

\subsubsection{Data Analysis}

Data analysis was performed using STATA software version 13.0 (Stata Corporation, College Station, TX, USA). This software has the advantage of directly including robust standard errors that account for the sampling design, i.e. cluster sampling owing to the sampling of school classes. Associations between dietary behaviour and substance use, physical activity, psychosocial, and socio-familial factors and overweight, obesity and overweight or obesity among school children were evaluated calculating odds ratios (OR). Unconditional logistic regression was used for evaluation of the impact of explanatory 
variables for overweight or obesity and obesity (binary dependent variables). All variables statistically significant at the $p<0.05$ levels in bivariate analyses were included in the multivariable models. In the analysis, weighted percentages are reported. The reported sample size refers to the sample that was asked the target question. The two-sided 95\% confidence intervals are reported. The $p$ values less or equal to $5 \%$ are used to indicate statistical significance. Both the reported $95 \%$ confidence intervals and the $p$ value are adjusted for the multi-stage stratified cluster sample design of the study.

\section{Results}

\subsection{Sample Characteristics}

The study response rate for the Fiji was 90\%, Kiribati $85 \%$, Samoa 79\%, Solomon Islands $85 \%$, Tonga $80 \%$, and Vanuatu $72 \%$. The final sample included 10,424 school-going adolescents predominantly 13-16 years old from Fiji, Kiribati, Samoa, Solomon Islands, Tonga, and Vanuatu; Kiribati, Samoa, Solomon Islands and Vanuatu are lower middle income countries and Fiji and Tonga upper lower middle income countries [29]. The study found a prevalence of overweight or obesity of $24.3 \%$ and obesity of $6.1 \%$ in six pacific island countries in Oceania. There was a large country variation in terms of overweight or obesity and obesity ranging from $12.0 \%$ and $0.4 \%$ in Vanuatu to $58.7 \%$ and $21.1 \%$ in Tonga, respectively. In terms of dietary behaviour and substance use, $40.3 \%$ consumed one or more carbonated soft drinks per day, $24 \%$ had three or more times fast foods per week, $49 \%$ had two or more fruits per day, $34.9 \%$ three of more servings of vegetables per day, $18.7 \%$ has consumed alcoholic beverages in the past month and $23.3 \%$ were current tobacco users. Regarding physical activity, $67.6 \%$ were physically inactive (less than $60 \mathrm{~min} /$ day), $39.2 \%$ did not walk or bike to school, $22.3 \%$ spent three or more hours sitting in a day, and $32.4 \%$ engaged in three or more days of physical education in a week. Regarding psychosocial factors, being bullied was the most frequent one, followed by suicidal ideation and having no close friends. Socio-familial influences were highest for parental or guardian supervision and peer support (see Table 1).

Table 1. Descriptive data of school-going adolescents aged predominantly 13-16 years $(\mathrm{N}=10,424)$.

\begin{tabular}{lcccc}
\hline \multirow{2}{*}{ Variable } & Sample & Overweight & Obesity & Overweight or Obesity \\
\cline { 2 - 5 } & $\mathrm{N}(\%)$ & $\%(95 \% \mathrm{CI})$ & $\%(95 \% \mathrm{CI})$ & $\%(95 \% \mathrm{CI})$ \\
\hline All & 10424 & $18.2(16.2-20.5)$ & $6.1(5.1-7.2)$ & $24.3(21.7-27.2)$ \\
Fiji & $1773(16.0)$ & $13.9(11.4-16.8)$ & $5.2(4.0-6.7)$ & $19.1(16.0-22.5)$ \\
Kiribati & $1582(15.2)$ & $32.5(29.6-35.4)$ & $7.4(5.7-9.6)$ & $39.9(36.5-43.4)$ \\
Samoa & $2418(23.2)$ & $32.6(30.0-35.4)$ & $19.3(16.8-22.2)$ & $52.0(48.3-55.6)$ \\
Solomon Islands & $1421(13.6)$ & $18.9(15.0-23.6)$ & $2.7(1.6-4.4)$ & $21.6(17.0-27.0)$ \\
Tonga & $2211(21.2)$ & $37.6(35.7-39.5)$ & $21.1(18.6-23.8)$ & $58.7(55.9-61.4)$ \\
Vanuatu & $1119(10.7)$ & $11.5(7.5-17.3)$ & $0.4(0.1-1.4)$ & $12.0(7.7-18.0)$ \\
Country income & & & & \\
Kiribati, Samoa, Solomon & $6540(62.7)$ & $20.5(17.5-23.9)$ & $5.0(3.7-6.8)$ & $25.6(21.5-30.1)$ \\
Islands and Vanuatu & & & & \\
Fiji and Tonga & $3884(37.3)$ & $16.4(13.9-19.4)$ & $6.9(5.9-8.4)$ & $23.3(20.0-27.0)$ \\
\hline
\end{tabular}


Table 1. Cont.

\begin{tabular}{|c|c|c|c|c|}
\hline \multirow{2}{*}{ Variable } & Sample & Overweight & Obesity & Overweight or Obesity \\
\hline & $\mathrm{N}(\%)$ & $\%(95 \% \mathrm{CI})$ & $\%(95 \% \mathrm{CI})$ & $\%(95 \% \mathrm{CI})$ \\
\hline \multicolumn{5}{|l|}{ Gender } \\
\hline Female & $5672(49.4)$ & $21.0(18.3-23.9)$ & $6.0(4.9-7.3)$ & $27.0(23.7-30.1)$ \\
\hline Male & $4566(50.6)$ & $15.5(13.5-17.8)$ & $6.2(4.9-7.7)$ & $21.7(18.8-24.8)$ \\
\hline \multicolumn{5}{|l|}{ Age in years } \\
\hline 13 or less & $2725(30.2)$ & $15.8(12.0-20.5)$ & $5.8(4.3-7.8)$ & $21.5(17.1-26.8)$ \\
\hline Age in years & $\mathrm{N}(\%)$ & $\%(95 \% \mathrm{CI})$ & $\%(95 \% \mathrm{CI})$ & $\%(95 \% \mathrm{CI})$ \\
\hline 14 & $3282(25.9)$ & $19.0(16.4-22.1)$ & $7.7(6.4-9.2)$ & $26.7(23.1-30.7)$ \\
\hline 15 & $2934(24.7)$ & $19.5(16.9-22.3)$ & $5.9(4.7-7.2)$ & $25.4(22.3-28.7)$ \\
\hline 16 or more & $1364(19.2)$ & $19.1(15.6-23.0)$ & $3.9(2.8-5.6)$ & $23.0(19.2-27.2)$ \\
\hline \multicolumn{5}{|c|}{ Dietary behaviour and substance use } \\
\hline $\begin{array}{l}\text { One or more carbonated } \\
\text { soft drinks per day }\end{array}$ & $3974(40.3)$ & $23.9(20.3-27.9)$ & $8.1(6.1-10.5)$ & $31.2(26.4-36.4)$ \\
\hline $\begin{array}{l}\text { Fast foods three or more } \\
\text { times per week }\end{array}$ & $2278(24.0)$ & $23.9(20.3-27.9)$ & $7.6(5.7-10.0)$ & $31.5(26.8-36.6)$ \\
\hline Fruits $2+$ a day & $4582(49.0)$ & $17.9(15.3-20.9)$ & $5.7(4.5-7.3)$ & $23.4(20.7-27.0)$ \\
\hline Vegetables $3+$ a day & $3444(34.9)$ & $18.2(15.6-21.1)$ & $5.9(4.8-7.4)$ & $24.1(21.0-27.5)$ \\
\hline $\begin{array}{l}\text { Most of the time or } \\
\text { always hunger }\end{array}$ & $1761(11.7)$ & $20.4(16.6-24.8)$ & $6.9(4.9-9.6)$ & $27.2(22.5-32.6)$ \\
\hline Alcohol use in past month & $2270(18.7)$ & $17.8(14.7-21.4)$ & $7.1(5.3-9.4)$ & $24.9(20.9-29.5)$ \\
\hline Tobacco use in past month & $2549(23.3)$ & $19.4(15.9-23.4)$ & $8.6(6.7-11.0)$ & $28.0(23.6-32.8)$ \\
\hline \multicolumn{5}{|l|}{ Physical activity } \\
\hline $\begin{array}{l}\text { Physical activity less than } \\
60 \text { min per day on at least } \\
\text { five days per week }\end{array}$ & $7283(67.6)$ & $18.6(16.2-21.3)$ & $6.4(5.3-7.8)$ & $25.0(22.0-28.3)$ \\
\hline $\begin{array}{l}\text { Not walk or bike to school } \\
\text { at least once a week }\end{array}$ & $4219(39.2)$ & $17.6(15.2-20.3)$ & $5.9(4.7-7.4)$ & $23.5(20.1-27.2)$ \\
\hline $\begin{array}{l}\text { Sedentary behaviour } \\
\text { (three hours or more a day) }\end{array}$ & $2698(22.3)$ & $19.6(17.0-22.5)$ & $6.8(5.4-8.5)$ & $26.4(23.0-30.0)$ \\
\hline $\begin{array}{l}\text { Physical education three or } \\
\text { more days a week }\end{array}$ & $2940(32.4)$ & $19.9(17.6-22.3)$ & $5.3(3.9-7.1)$ & $25.2(22.1-28.5)$ \\
\hline \multicolumn{5}{|l|}{ Psychosocial factors } \\
\hline Loneliness & $1505(11.3)$ & $17.9(14.6-21.8)$ & $7.0(4.8-9.9)$ & $24.9(20.7-29.5)$ \\
\hline Anxiety or worried & $1614(10.7)$ & $18.9(15.1-23.4)$ & $6.7(4.7-9.3)$ & $25.5(20.1-31.8)$ \\
\hline Suicidal ideation & $2072(24.1)$ & $21.0(18.0-24.4)$ & $5.8(4.2-8.1)$ & $26.8(22.9-31.2)$ \\
\hline No close friends & $1018(12.4)$ & $14.2(11.1-17.9)$ & $8.0(5.1-12.4)$ & $22.2(17.3-28.1)$ \\
\hline Being bullied & $5257(61.6)$ & $18.4(16.2-20.9)$ & $5.9(4.4-7.9)$ & $24.3(20.9-28.0)$ \\
\hline \multicolumn{5}{|l|}{ Social-familial factors } \\
\hline $\begin{array}{l}\text { Peer support (most of the } \\
\text { time or always) }\end{array}$ & $2733(29.7)$ & $24.5(20.9-28.5)$ & $8.6(6.7-11.1)$ & $33.1(28.2-38.4)$ \\
\hline
\end{tabular}


Table 1. Cont.

\begin{tabular}{lcccc}
\hline Variable & Sample & Overweight & Obesity & Overweight or Obesity \\
\cline { 2 - 5 } & $\mathrm{N}(\%)$ & $\%(95 \% \mathrm{CI})$ & $\%(95 \% \mathrm{CI})$ & $\%(95 \% \mathrm{CI})$ \\
\hline $\begin{array}{l}\text { Parental or guardian } \\
\text { supervision (most of the } \\
\text { time or always) }\end{array}$ & $2964(34.5)$ & $25.2(21.7-29.1)$ & $8.1(6.3-10.3)$ & $33.3(28.5-38.6)$ \\
$\begin{array}{l}\text { Parental or guardian } \\
\text { connectedness (most of the } \\
\text { time or always) }\end{array}$ & $2987(23.6)$ & $23.8(19.5-28.6)$ & $7.6(5.6-10.3)$ & $31.1(25.3-38.0)$ \\
$\begin{array}{l}\text { Parental or guardian } \\
\text { bonding (most of the } \\
\text { time or always) }\end{array}$ & $2425(27.4)$ & $25.4(21.8-29.3)$ & $8.1(6.4-10.2)$ & $33.5(28.8-38.5)$ \\
\hline
\end{tabular}

\subsection{Association with Overweight, Obesity, and Overweight or Obesity}

In multivariate analysis, being female was associated with overweight and overweight or obesity but not with obesity. Carbonated soft drink use was associated with obesity. Sedentary behaviour was associated with overweight or obesity, and having three or more days a week physical education was associated with overweight. Psychosocial factors (suicidal ideation) were associated with overweight and overweight or obesity but not with obesity. In terms of social-familial factors, having close friends and peer support was associated with overweight and obesity, respectively, parental or guardian supervision was associated with overweight, and parental or guardian bonding was associated with overweight or obesity. Further, in bivariate analyses, tobacco use was associated with obesity and living in an upper middle country was marginally significantly associated with obesity. Other dietary behaviour (eating vegetables, hunger), alcohol use, physical activity, and other psychosocial factors (anxiety, loneliness, being bullied) were not found to be associated with overweight, obesity and overweight or obesity (see Tables 2 and 3).

Table 2. Overweight and obesity regression model.

\begin{tabular}{|c|c|c|c|c|}
\hline \multirow{2}{*}{ Variable } & \multicolumn{2}{|c|}{ Overweight } & \multicolumn{2}{|c|}{ Obese } \\
\hline & $\mathrm{OR}^{1}(95 \% \mathrm{CI})$ & $\operatorname{AOR}^{2}(95 \% \mathrm{CI})$ & $\mathrm{OR}^{1}(95 \% \mathrm{CI})$ & $\mathrm{AOR}^{2}(95 \% \mathrm{CI})$ \\
\hline \multicolumn{5}{|l|}{ Gender } \\
\hline Female & 1.00 & 1.00 & 1.00 & \multirow{2}{*}{ - } \\
\hline Male & $0.69(0.59-0.81) * * *$ & $0.62(0.50-0.77) * *$ & $1.03(0.78-1.36)$ & \\
\hline \multicolumn{5}{|l|}{ Age in years } \\
\hline 13 or less & 1.00 & \multirow{4}{*}{-} & 1.00 & \multirow{4}{*}{ 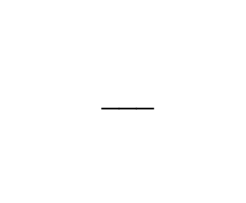 } \\
\hline 14 & $1.26(0.91-1.74)$ & & $1.35(0.98-1.87)$ & \\
\hline 15 & $1.29(0.91-1.84)$ & & $1.01(0.71-1.45)$ & \\
\hline 16 or more & $1.26(0.85-1.86)$ & & $0.67(0.41-1.09)$ & \\
\hline
\end{tabular}


Table 2. Cont.

\begin{tabular}{|c|c|c|c|c|}
\hline \multirow{2}{*}{ Variable } & \multicolumn{2}{|c|}{ Overweight } & \multicolumn{2}{|c|}{ Obese } \\
\hline & $\mathrm{OR}^{1}(95 \% \mathrm{CI})$ & $\operatorname{AOR}^{2}(95 \% \mathrm{CI})$ & $\mathrm{OR}^{1}(95 \% \mathrm{CI})$ & $\operatorname{AOR}^{2}(95 \% \mathrm{CI})$ \\
\hline \multicolumn{5}{|l|}{ Country income } \\
\hline $\begin{array}{l}\text { Lower Middle Income } \\
\text { Country }\end{array}$ & 1.00 & & 1.00 & \\
\hline $\begin{array}{l}\text { Upper Middle Income } \\
\text { Country }\end{array}$ & $0.76(0.58-1.01)$ & & $1.40(0.95-2.04)$ & \\
\hline \multicolumn{5}{|l|}{$\begin{array}{l}\text { Dietary behaviour and } \\
\text { substance use }\end{array}$} \\
\hline $\begin{array}{l}\text { One or more carbonated } \\
\text { soft drinks per day }\end{array}$ & $1.06(0.92-1.23)$ & - & $1.32(1.09-1.61) * *$ & $1.29(1.08-1.54) * *$ \\
\hline $\begin{array}{l}\text { Fast foods three or more } \\
\text { times per week }\end{array}$ & $1.10(0.92-1.32)$ & - & $1.12(0.89-1.41)$ & - \\
\hline Fruits $2+$ a day & $0.97(0.77-1.22)$ & - & $0.91(0.72-1.15)$ & - \\
\hline Vegetables $3+$ a day & $0.99(0.86-1.15)$ & - & $0.97(0.77-1.22)$ & - \\
\hline $\begin{array}{c}\text { Most of the time or always } \\
\text { hunger }\end{array}$ & $1.17(0.94-1.47)$ & - & $1.16(0.83-1.62)$ & - \\
\hline Alcohol use in past month & $1.02(0.83-1.26)$ & - & $1.23(0.88-1.71)$ & - \\
\hline Tobacco use in past month & $1.02(0.83-1.26)$ & - & $1.36(1.00-1.83) *$ & $1.02(0.78-1.32)$ \\
\hline \multicolumn{5}{|l|}{ Physical activity } \\
\hline $\begin{array}{l}\text { Physical activity less than } \\
60 \text { min per day on at least } \\
\text { five days per week }\end{array}$ & $1.09(0.91-1.32)$ & - & $1.29(0.94-1.76)$ & - \\
\hline $\begin{array}{c}\text { Not walk or bike to school } \\
\text { at least once a week }\end{array}$ & $0.93(0.77-1.12)$ & - & $0.95(0.73-1.24)$ & - \\
\hline $\begin{array}{l}\text { Sedentary behaviour (three } \\
\text { hours or more per day) }\end{array}$ & $1.14(1.00-1.29) *$ & $1.03(0.82-1.29)$ & $1.19(0.93-1.52)$ & - \\
\hline $\begin{array}{c}\text { Physical education three or } \\
\text { more days/week }\end{array}$ & $1.18(1.03-1.35) *$ & $1.23(1.00-1.50) *$ & $0.83(0.61-1.11)$ & - \\
\hline \multicolumn{5}{|l|}{ Psychosocial factors } \\
\hline Loneliness & $1.00(0.81-1.22)$ & - & $1.18(0.83-1.68)$ & - \\
\hline Anxiety or worried & $1.05(0.82-1.34)$ & - & $1.13(0.76-1.67)$ & - \\
\hline Suicidal ideation & $1.42(1.21-1.66) * * *$ & $1.44(1.14-1.81) * *$ & $1.26(0.89-1.78)$ & - \\
\hline No close friends & $0.72(0.56-0.92) * *$ & $0.50(0.43-0.80) * * *$ & $1.40(0.86-2.20)$ & - \\
\hline Being bullied & $1.05(0.88-1.25)$ & - & $0.94(0.63-1.40)$ & - \\
\hline \multicolumn{5}{|l|}{ Social-familial factors } \\
\hline $\begin{array}{l}\text { Peer support (most of the } \\
\text { time or always) }\end{array}$ & $1.17(0.97-1.41)$ & - & $1.45(1.16-1.81) * * *$ & $1.43(1.12-1.83) * *$ \\
\hline $\begin{array}{l}\text { Parental or guardian } \\
\text { supervision (most of } \\
\text { the time or always) }\end{array}$ & $1.26(1.07-1.50) * *$ & $1.23(1.00-1.50) *$ & $1.13(1.10-1.83) * *$ & $1.08(0.86-1.35)$ \\
\hline $\begin{array}{l}\text { Parental or guardian } \\
\text { connectedness (most of } \\
\text { the time or always) }\end{array}$ & $1.11(0.89-1.39)$ & - & $1.16(0.86-1.58)$ & - \\
\hline
\end{tabular}


Table 2. Cont.

\begin{tabular}{|c|c|c|c|c|}
\hline \multirow{2}{*}{ Variable } & \multicolumn{2}{|c|}{ Overweight } & \multicolumn{2}{|c|}{ Obese } \\
\hline & $\mathrm{OR}^{1}(95 \% \mathrm{CI})$ & $\operatorname{AOR}^{2}(95 \%$ CI) & $\mathrm{OR}^{1}(95 \% \mathrm{CI})$ & $\operatorname{AOR}^{2}(95 \% \mathrm{CI})$ \\
\hline $\begin{array}{l}\text { Parental or guardian } \\
\text { bonding (most of the } \\
\text { time or always) }\end{array}$ & $1.26(1.06-1.49) * *$ & $1.27(0.99-1.63)$ & $1.29(1.06-1.57) *$ & $1.15(0.94-1.42)$ \\
\hline
\end{tabular}

Table 3. Overweight or obesity regression model.

\begin{tabular}{|c|c|c|}
\hline \multirow[t]{2}{*}{ Variable } & \multicolumn{2}{|l|}{ Overweight or Obese } \\
\hline & $\mathrm{OR}^{1}(95 \% \mathrm{CI})$ & $\operatorname{AOR}^{2}(95 \% \mathrm{CI})$ \\
\hline \multicolumn{3}{|l|}{ Gender } \\
\hline Female & 1.00 & 1.00 \\
\hline Male & $0.75(0.62-0.89) * * *$ & $0.63(0.53-0.74) * * *$ \\
\hline \multicolumn{3}{|l|}{ Age in years } \\
\hline 13 or less & 1.00 & - \\
\hline 14 & $1.33(0.99-1.78)$ & \\
\hline 15 & $1.24(0.90-1.69)$ & \\
\hline 16 or more & $1.09(0.76-1.56)$ & \\
\hline \multicolumn{3}{|l|}{ Country income } \\
\hline Lower Middle Income Country & 1.00 & - \\
\hline Upper Middle Income Country & $0.89(0.66-1.19)$ & \\
\hline \multicolumn{3}{|l|}{ Dietary behaviour and substance use } \\
\hline One or more carbonated soft drinks per day & $1.15(0.99-1.34)$ & - \\
\hline Fast foods three or more times per week & $1.13(0.96-1.32)$ & - \\
\hline Fruits $2+$ a day & $0.95(0.80-1.12)$ & - \\
\hline Vegetables $3+$ a day & $0.98(0.85-1.14)$ & - \\
\hline Most of the time or always hunger & $1.19(0.95-1.49)$ & - \\
\hline Alcohol use in past month & $1.05(0.88-1.26)$ & - \\
\hline Tobacco use in past month & $1.13(0.93-1.37)$ & - \\
\hline \multicolumn{3}{|l|}{ Physical activity } \\
\hline $\begin{array}{l}\text { Physical activity less than } 60 \text { min per day on at least five days } \\
\text { per week }\end{array}$ & $1.16(0.99-1.36)$ & - \\
\hline Not walk or bike to school at least once a week & $0.93(0.77-1.13)$ & - \\
\hline Sedentary behaviour (three hours of more per day) & $1.17(1.03-1.34) *$ & $1.21(1.01-1.46) *$ \\
\hline Physical education three or more days/week & $1.08(0.94-1.25)$ & - \\
\hline \multicolumn{3}{|l|}{ Psychosocial factors } \\
\hline Loneliness & $1.05(0.88-1.26)$ & - \\
\hline Anxiety or worried & $1.08(0.81-1.45)$ & - \\
\hline Suicidal ideation & $1.42(1.24-1.63) * * *$ & $1.38(1.13-1.68) * *$ \\
\hline No close friends & $0.87(0.66-1.16)$ & - \\
\hline Being bullied & $1.02(0.85-1.22)$ & - \\
\hline \multicolumn{3}{|l|}{ Social-familial factors } \\
\hline Peer support (most of the time or always) & $1.28(1.08-1.53) * *$ & $1.06(0.86-1.31)$ \\
\hline
\end{tabular}


Table 3. Cont.

\begin{tabular}{lll}
\hline Variable & Overweight or Obese \\
\hline Parental or guardian supervision (most of the time or always) & $1.33(1.13-1.58) * * *$ & $1.17(0.94-1.45)$ \\
Parental or guardian connectedness (most of the time or always) & $1.14(0.89-1.47)$ & - \\
Parental or guardian bonding (most of the time or always) & $1.31(1.12-1.54) * * *$ & $1.29(1.06-1.56) * *$ \\
\hline${ }^{1} \mathrm{OR}=$ Odds Ratio; ${ }^{2} \mathrm{AOR}=$ Adjusted Odds Ratio; CI = Confidence Interval. $* * *$ & $p<0.001 ; * * p<0.01 ;$ \\
&
\end{tabular}

\section{Discussion}

The study found a high prevalence of overweight or obesity of $24.3 \%$ among school-going adolescents (27.0\% in girls and $21.7 \%$ in boys) across six Pacific Island countries in Oceania, ranging from $12.0 \%$ in Vanuatu to $58.7 \%$ in Tonga. The overall prevalence of overweight or obesity and country variation, compare largely with previous studies in the region [7-10], is higher than in developing countries in general (13.4\% in girls $12.9 \%$ in boys) and similar to overweight or obesity rates among children and adolescents in developed countries (22.6\% in girls and $23.8 \%$ in boys) [10]. Some studies [30,31] found that overweight was positively related to national income, while in this study higher country income status was only marginally significantly associated with obesity and not overweight. Country variation in the prevalence of adolescent obesity may be related to differences in the degree of rapid social change [32] and sociocultural factors related to dietary patterns, physical activity, and body size [33] needing further investigation.

This study found a higher prevalence rate of overweight and overweight or obesity in female than male adolescents, which concurs with studies among adolescents in low and middle income countries e.g., $[10,15,16]$. Possible reasons for this may be cultural differences in beliefs regarding body image. McCabe et al. [34] found that Fijian and Tongan adolescents were more likely to value a large body [32]. Further, Poskitt [35] found that in societies in transition, girls may be more susceptible to overweight than boys during the health transition, as they grow up. Interestingly, however, that overall there was no significant gender difference in the prevalence of obesity in this study. However, in lower middle income study countries (Kiribati, Samoa, Solomon Islands and Vanuatu) the prevalence of obesity was significantly higher in girls (5.7\%) than in boys (4.4\%), while in upper middle income study countries (Fiji and Tonga) the prevalence of obesity was significantly higher in boys (7.6\%) than in girls (6.2\%) (analysis not shown). This finding concurs with some studies e.g., [36] in most high income countries in Europe, with boys having higher rates of overweight or obesity than girls.

Further, regarding dietary behaviour, this study found an association between the consumption of sugar-sweetened beverages (SSBs) and obesity, which is confirmed from a majority of studies in a review [17]. SSBs are the primary source of added sugar in the diet of children and adolescents [17]. A high per capita soft drink consumption in Pacific Island countries and territories has also been confirmed by trade data [37]. Although this study did not find an association between physical inactivity and overweight and obesity, high sedentary behaviour was found to be associated with overweight or obesity, as also found in some previous studies [20]. In bivariate analysis tobacco use was associated with obesity, which is conforming to some previous studies [22,23]. There may be a belief that adolescents, particularly girls, use smoking as a means to control body weight [23]. 
In terms of psychosocial factors, having suicidal ideation was significantly associated with overweight and overweight or obesity but not with obesity in this study. Zeller et al. [38] found that relative to healthy weight, being obese was associated with significantly greater risk for adolescent engagement in suicidal ideation, but was unrelated to suicide attempts. The importance of linking psychosocial stressors and childhood obesity has been emphasized [39].

A positive parenting style (parental or guardian supervision and connectedness) were found in this study to be associated with overweight and overweight or obesity, respectively, while a previous study found a negative parenting style (authoritarian parents) was associated with childhood obesity [26]. Moreover, having close friends and positive peer support was found to be associated with overweight and obesity, respectively. It is possible that socio-cultural values of body size contribute to this. Similarly, Petersen et al. [7] found a positive association between the psychosocial aspect of health-related quality of life and obesity in secondary school children in Fiji. Traditionally, some groups in Fiji perceive a large body size as desirable and also of being cared for [7]. More research is needed to investigate social-familial influences on childhood obesity.

Unlike previous studies [18-20], this study did not find an association between physical inactivity, not walking or cycling to school, specific dietary behaviours such as frequently consumed fast food and lack of fruit consumption and overweight and obesity. It is possible that because of the high prevalence of physical inactivity, no association was found.

\section{Study Strength and Limitations}

A strength of the use of GSHS was standardized methods and questionnaires were used across study countries. Further, a validation study of the health-risk behaviour component of the GSHS questionnaire found good validity in one of the Oceania study countries (Fiji) [40]. The study survey was cross-sectional and therefore no causal inferences can be made. The cut-offs used with self-reported BMI may lead to underestimation or overestimation of overweight and obesity [38]. The BMI was assessed by self-reported weight and height and could have included anthropometry to evaluate weight status. Dietary behaviour was not assessed with a validated food questionnaire, which may be included in future studies. Moreover, for the assessment of some concepts such as psychosocial factors, only one-item measures were used. In addition, several factors such as body composition (body fat) known to be associated with obesity status were not assessed.

\section{Conclusions}

High prevalence rates of overweight or obesity were found among school-going adolescents in six Pacific Island countries in Oceania. Increased strategies are needed to prevent and treat overweight and obesity in youth.

\section{Acknowledgments}

We are grateful to the World Health Organization and the Centers for Disease Control and Prevention for making the data publicly available. We also thank the country coordinators from Fiji (Sulueti Duvaga), Kiribati (Marutaake Karawaiti), Samoa (Ms Ualesi), Solomon Islands 
(Nevalyn Laesango), Tonga (Eva Mafi), and Vanuatu (Joe Higgs Kalo) for collecting the GSHS data. The Ministries of Education and Health and the study participants in the GSHS in the six Oceanian countries are acknowledged. The governments of the respective study countries and the World Health Organization did not influence the analysis nor did they have an influence on the decision to publish these findings.

\section{Author Contributions}

All authors (Supa Pengpid and Karl Peltzer) have participated in this work via study of analysis design and interpretation of data, and writing of the manuscript.

\section{Conflicts of Interest}

The authors declare no conflict of interest.

\section{References}

1. Lobstein, T.; Jackson-Leach, R.; Moodie, M.L.; Hall, K.D.; Gortmaker, S.L.; Swinburn, B.A.; James, W.P.; Wang, Y.; McPherson, K. Child and adolescent obesity: Part of a bigger picture. Lancet 2015, 385, 2510-2520.

2. Wang, Y.; Lim, H. The global childhood obesity epidemic and the association between socio-economic status and childhood obesity. Int. Rev. Psychiatry 2012, 24, 176-188.

3. Olszowy, K.M.; Pomer, A.; Dancause, K.N.; Sun, C.; Silverman, H.; Lee, G.; Chan, C.W.; Tarivonda, L.; Regenvanu, R.; Kaneko, A.; et al. Impact of modernization on adult body composition on five islands of varying economic development in Vanuatu. Am. J. Hum. Biol. 2015, 5, doi:10.1002/ajhb.22734.

4. Lin, S.; Tukana, I.; Linhart, C.; Morrell, S.; Taylor, R.; Vatucawaqa, P.; Magliano, D.J.; Zimmet, P. Diabetes and obesity trends in Fiji over 30 years. J. Diabetes. 2015, 7, doi:10.1111/ 1753-0407.12326.

5. Hawley, N.L.; McGarvey, S.T. Obesity and diabetes in Pacific Islanders: The current burden and the need for urgent action. Curr. Diab. Rep. 2015, 15, doi:10.1007/s11892-015-0594-5.

6. Hawley, N.L.; Minster, R.L.; Weeks, D.E.; Viali, S.; Reupena, M.S.; Sun, G.; Cheng, H.; Deka, R.; Mcqarvey, S.T. Prevalence of adiposity and associated cardiometabolic risk factors in the Samoan genome-wide association study. Am. J. Hum. Biol. 2014, 26, 491-501.

7. Petersen, S.; Moodie, M.; Mavoa, H.; Waqa, G.; Goundar, R.; Swinburn, B. Relationship between overweight and health-related quality of life in secondary school children in Fiji: Results from a cross-sectional population-based study. Int. J. Obes. 2014, 38, 539-546.

8. Fukuyama, S.; Inaoka, T.; Matsumura, Y.; Yamauchi, T.; Natsuhara, K.; Kimura, R.; Ohtsuka, R. Anthropometry of 5-19-year-old Tongan children with special interest in the high prevalence of obesity among adolescent girls. Ann. Hum. Biol. 2005, 32, 714-723.

9. Dancause, K.N.; Vilar, M.; Chan, C.; DeHuff, C.; Wilson, M.; Soloway, L.E.; Tarivonda, L.; Regenvanu, R.; Kaneko, A.; Garruto, R.M.; et al. Patterns of childhood and adolescent overweight and obesity during health transition in Vanuatu. Public Health Nutr. 2012, 15, 158-166. 
10. Ng, M.; Fleming, T.; Robinson, M.; Thomson, B.; Graetz, N.; Margono, C.; Mullany, E.C.; Biryukov, S.; Abbafati, C.; Abera, S.F.; et al. Global, regional, and national prevalence of overweight and obesity in children and adults during 1980-2013: A systematic analysis for the Global Burden of Disease Study 2013. Lancet 2014, 384, 766-781.

11. Reilly, J.J.; Kelly, J. Long-term impact of overweight and obesity in childhood and adolescence on morbidity and premature mortality in adulthood: Systematic review. Int. J. Obes. 2011, 35, 891-898.

12. De Onis, M.; Lobstein, T. Defining obesity risk status in the general childhood population: Which cut-offs should we use? Int. J. Pediatr. Obes. 2010, 5, 458-460.

13. Garza, J.R.; Pérez, E.A.; Prelip, M.; McCarthy, W.J.; Feldman, J.M.; Canino, G.; Ortega, A.N. Occurrence and correlates of overweight and obesity among island Puerto Rican youth. Ethn. Dis. 2011, 21, 163-169.

14. Nichols, S.D.; Cadogan, F. BMI-based obesity cutoffs and excess adiposity in a Caribbean adolescent population of African origin. Eur. J. Clin. Nutr. 2009, 63, 253-258.

15. Kimani-Murage, E.W.; Kahn, K.; Pettifor, J.M.; Tollman, S.M.; Klipstein-Grobusch, K.; Norris, S.A. Predictors of adolescent weight status and central obesity in rural South Africa. Public Health Nutr. 2011, 14, 1114-1122.

16. Pengpid, S.; Peltzer, K. Childhood overweight and social correlates among school-going adolescents in Dominica and Jamaica. Afr. J. Phys. Health. Educ. Recr. Dance 2014, 20, 636-645.

17. Keller, A.; Bucher Della Torre, S. Sugar-Sweetened Beverages and Obesity among Children and Adolescents: A Review of Systematic Literature Reviews. Child. Obes. 2015, 11, 338-346.

18. Moreno, L.A.; Rodríguez, G. Dietary risk factors for development of childhood obesity. Curr. Opin. Clin. Nutr. Metab. Care. 2007, 10, 336-341.

19. Francis, D.K.; Van den Broeck, J.; Younger, N.; McFarlane, S.; Rudder, K.; Gordon-Strachan, G.; Grant, A.; Johnson, A.; Tulloch-Reid, M.; Wilks, R. Fast-food and sweetened beverage consumption: Association with overweight and high waist circumference in adolescents. Public Health Nutr. 2009, 12, 1106-1114.

20. Mistry, S.K.; Puthussery, S. Risk factors of overweight and obesity in childhood and adolescence in South Asian countries: A systematic review of the evidence. Public Health 2015, 129, 200-209.

21. Janssen, I.; Katzmarzyk, P.T.; Boyce, W.F.; King, M.A.; Pickett, W. Overweight and obesity in Canadian adolescents and their associations with dietary habits and physical activity patterns. J. Adolesc. Health 2004, 35, 360-367.

22. Peltzer, K.; Pengpid, S. Overweight and obesity and associated factors among school-aged adolescents in Ghana and Uganda. Int. J. Environ. Res. Public Health 2011, 8, 3859-3870.

23. Potter, B.K.; Pederson, L.L.; Chan, S.S.; Aubut, J.A.; Koval, J.J. Does a relationship exist between body weight, concerns about weight, and smoking among adolescents? An integration of the literature with an emphasis on gender. Nicotine Tob. Res. 2004, 6, 397-425.

24. Vámosi, M.; Heitmann, B.L.; Kyvik, K.O. The relation between an adverse psychological and social environment in childhood and the development of adult obesity: a systematic literature review. Obes. Rev. 2010, 11, 177-184.

25. Spruijt-Metz, D. Etiology, Treatment and Prevention of Obesity in Childhood and Adolescence: A Decade in Review. J. Res. Adolesc. 2011, 21, 129-152. 
26. Kakinami, L.; Barnett, T.A.; Séguin, L.; Paradis, G. Parenting style and obesity risk in children. Prev. Med. 2015, 75, 18-22.

27. Centers for Disease Control (CDC) The Global School and Health Survey background. Available online: http://www.cdc.gov/gshs/background/index (accessed on 18 August 2015).

28. Cole, T.J.; Bellizzi, M.C.; Flegal, K.M.; Dietz, W.H. Establishing a standard definition for child overweight and obesity worldwide: International survey. BMJ. 2000, 6, 1240-1243.

29. World Bank. Countries and economie, 2014. Available online: http://data.worldbank.org/country (accessed on 18 August 2015).

30. Popkin, B.M.; Adair, L.S.; Ng, S.W. Global nutrition transition and the pandemic of obesity in developing countries. Nutr. Rev. 2012, 70, 3-21.

31. Philipson, T.J.; Posner, R.A. The long-run growth in obesity as a function of technological change. Perspect. Biol. Med. 2003, 46, S87-S107.

32. Becker, A.E., Gilman, S.E., Burwell, R.A. Changes in prevalence of overweight and in body image among Fijian women between 1989 and 1998. Obes. Res. 2005, 13,110-117.

33. Mavoa, H.M.; McCabe, M. Sociocultural factors relating to Tongans' and Indigenous Fijians' patterns of eating, physical activity and body size. Asia Pac. J. Clin. Nutr. 2008, 17, 375-384.

34. McCabe, M.P.; Waqa, G.; Dev, A.; Cama, T.; Swinburn, B.A. The role of cultural values and religion on views of body size and eating practices among adolescents from Fiji, Tonga, and Australia. Br. J. Health Psychol. 2013, 18, 383-394.

35. Poskitt, E.M. Childhood obesity in low- and middle-income countries. Paediatr. Int. Child. Health 2014, 34, 239-249.

36. Haug, E.; Rasmussen, M.; Samdal, O.; Iannotti, R.; Kelly, C.; Borraccino, A.; Vereecken, C.; Melkevik, O.; Lazzeri, G.; Giacchi, M.; et al. HBSC Obesity Writing Group. Overweight in school-aged children and its relationship with demographic and lifestyle factors: Results from the WHO-Collaborative Health Behaviour in School-aged Children (HBSC) study. Int. J. Public Health 2009, 54, 167-179.

37. Pak, N.; Mcdonald, A.M.; McKenzie, J.; Tukuitonga, C. Soft drink consumption in Pacific Island countries and territories: A review of trade data. Pac. Health Dialog. 2014, 20, 59-66.

38. Zeller, M.H.; Reiter-Purtill, J.; Jenkins, T.M.; Ratcliff, M.B. Adolescent suicidal behavior across the excess weight status spectrum. Obesity. 2013, 21, 1039-1045.

39. Gundersen, C.; Mahatmya, D.; Garasky, S.; Lohman, B. Linking psychosocial stressors and childhood obesity. Obes. Rev. 2011, 12, e54-e63.

40. Becker, A.E.; Roberts, A.L.; Perloe, A.; Bainivualiku, A.; Richards, L.K.; Gilman, S.E.; Striegel-Moore, R.H. Youth health-risk behavior assessment in Fiji: the reliability of Global School-based Student Health Survey content adapted for ethnic Fijian girls. Ethn. Health. 2010, $157,371-375$.

(C) 2015 by the authors; licensee MDPI, Basel, Switzerland. This article is an open access article distributed under the terms and conditions of the Creative Commons Attribution license (http://creativecommons.org/licenses/by/4.0/). 